\title{
INDUCIBLE CLINDAMYCIN RESISTANT STAPHYLOCOCCUS AUREUS ISOLATES FROM TERTIARY CARE HOSPITAL, BETTIAH, INDIA
}

\author{
Kali Charan Rajak1, Chandan Kumar Poddar², Rajiv Kumar³, Awadhesh Kumar Jha ${ }^{4}$
}

1 Tutor, Department of Pharmacology, Government Medical College, Bettiah, Bihar, India.

${ }^{2}$ Tutor, Department of Microbiology, Lord Buddha Koshi Medical College and Hospital, Saharsa, Bihar, India.

${ }_{3}^{3}$ Associate Professor, Department of Pathology, Lord Buddha Koshi Medical College and Hospital, Saharsa, Bihar, India.

${ }^{4}$ Associate Professor, Department of Pharmacology, Government Medical College, Bettiah, Bihar, India.

\section{BACKGROUND}

ABSTRACT

Staphylococcus aureus is a frequent cause of bacterial infections in both developed and developing countries. The Clinical and Laboratory Standards Institute (CLSI) recommends D-test, which is a phenotypic screening method for inducible Clindamycin resistance.

Therefore, all erythromycin resistant $S$. aureus should be tested for inducible Clindamycin resistance to prevent Clindamycin treatment failures and to report prevalence resistant phenotypes which varies widely.

\section{MATERIALS AND METHODS}

This cross-sectional study was conducted for a period of one year from January 2017 to January 2018 . We analysed 125 nonduplicate consecutive isolates of $S$. aureus isolated from various clinical specimens like pus, wound swab, aspirates, blood and sterile fluids. A total of $125 \mathrm{~S}$. aureus isolates derived from wound infection were evaluated for antimicrobial susceptibility testing by Kirby-Bauer disk diffusion method. Methicillin Resistance was detected using Cefoxitin (30 $\mu \mathrm{g})$ disk and inducible Clindamycin resistance was determined in all erythromycin resistant isolates by using D-zone test.

\section{RESULTS}

Out of 125 S. aureus isolates of the MRSA 46 (36.6\%) were derived from respective Pus samples 19 (41.53\%), the S. aureus isolates derived from Wound samples were MRSA 8 (18.03\%), the S. aureus isolates derived from Blood samples were MRSA 10 (22.40\%), the $S$. aureus isolates derived from Miscellaneous samples were MRSA $6(13.66 \%)$ and the $S$. aureus isolates derived from urine samples were MRSA 2 (3.75\%). A total of 26 S. aureus isolates showed inducible Clindamycin resistance by giving a positive D-zone test; hence, its prevalence was found to be $21.00 \%$ (26/125) with percentage distribution of cMLSB phenotype and MS phenotypes in all S. aureus isolates as $19.4 \%$ and $24.6 \%$ respectively. The susceptible phenotype (E-S and CD-S) predominated in MSSA (39.75\%) as compared to MRSA (13.11\%). Whereas, the constitutive resistant (cMLSB) predominated in MRSA (50.27\%) as compared to MSSA (15.46\%). Both the MS phenotype and the inducible resistant (iMLSB) phenotypes predominated in MSSA (19.87 and 24.92\%, respectively) as compared to MRSA (22.40\% and $14.20 \%$, respectively). The antimicrobial susceptibility test result of all the $105 \mathrm{~S}$. aureus isolates with iMLSB phenotype revealed that they were $100 \%$ sensitive to Vancomycin and Linezolid with moderate sensitivity (71.14\%) to Gentamicin, Cefuroxime and least sensitivity (23.81\%) to Doxycycline and $20.95 \%$ to Ciprofloxacin.

\section{CONCLUSION}

Due to high prevalence of Erythromycin resistance amongst $S$. aureus isolates, we suggest that D-zone test should be routinely done in all laboratories for appropriate prescription of Clindamycin and thereby preventing emergence of inducible resistant strains and treatment failure.

\section{KEY WORDS}

Staphylococcus aureus, Inducible Clindamycin Resistance, Wound Infection.

HOW TO CITE THIS ARTICLE: Rajak KC, Poddar CK, Kumar R, et al. Inducible clindamycin resistant staphylococcus aureus isolates from tertiary care hospital, Bettiah, India. J. Evolution Med. Dent. Sci. 2018;7(36):3984-3990, DOI: 10.14260/jemds/2018/890

\section{BACKGROUND}

Staphylococcus aureus can produce a wide variety of diseases, from relatively benign skin infections such as folliculitis and furunculosis to deep-seated and life-threatening conditions

'Financial or Other Competing Interest': None.

Submission 28-07-2018, Peer Review 20-08-2018,

Acceptance 27-08-2018, Published 03-09-2018.

Corresponding Author:

Dr. Chandan Kumar Poddar,

Tutor,

Department of Microbiology,

Lord Buddha Koshi Medical College and Hospital,

Saharsa, Bihar, India.

E-mail: chandan_microbiology@yahoo.co.in

DOI: $10.14260 /$ jemds $/ 2018 / 890$

\section{(c) $(1)$}

including cellulitis, deep abscesses, osteomyelitis, pneumonia, sepsis and endocarditis. Staphylococcus aureus is a frequent cause of bacterial infections in both developed and developing countries. ${ }^{1}$ The MLS $_{B}$ resistant phenotype in S. aureus can be either constitutive $\operatorname{MLS}_{\mathrm{B}}\left(\mathrm{CMLS}_{\mathrm{B}}\right)$ or inducible $\mathrm{MLS}_{\mathrm{B}}\left(\mathrm{iMLS} \mathrm{S}_{\mathrm{B}}\right.$ ). Staphylococci that express ribosomal methylase $(\mathrm{erm})$ genes may exhibit in vitro resistance to Erythromycin, Clindamycin and other drugs of MLS $\mathrm{B}_{\mathrm{B}}$ group. This resistance is referred to as the $\mathrm{CMLS}_{\mathrm{B}}$ phenotype. However, in some Staphylococci, those express erm genes require an inducing agent to synthesise methylase for Clindamycin resistance. This type is referred to as iMLS $_{\mathrm{B}}$ phenotype. These organisms are resistant to erythromycin and falsely susceptible to Clindamycin in vitro. ${ }^{2}$ 
This type of inducible Clindamycin resistance cannot be detected by standard Kirby-Bauer disk diffusion method, broth microdilution testing, automated susceptibility testing devices or Epsilometer test. ${ }^{3}$ Thus, falsely susceptible Clindamycin will lose its effectiveness in vivo and thereby increase the chance of therapeutic failures. 4

The double disk approximation test ( $D$-test) involves the placement of an Erythromycin disk in proximity to the disk containing Clindamycin. As the Erythromycin diffuses through the agar, the resistance to the clindamycin is induced, resulting in a flattening or blunting of the Clindamycin zone of inhibition adjacent to the Erythromycin disk, giving an "SO" shape to the zone. The Clinical and Laboratory Standards Institute (CLSI) recommends $D$-test, which is a phenotypic screening method for inducible Clindamycin resistance. 5 Therefore, all erythromycin resistant $S$. aureus should be tested for inducible Clindamycin resistance to prevent Clindamycin treatment failures and to report prevalent resistant phenotypes, which varies widely. The present study was aimed at determining the constitutive and inducible Clindamycin resistance in $S$. aureus isolated from various clinical specimens at a tertiary care hospital in Bettiah, India.

\section{MATERIALS AND METHODS}

This cross-sectional study was conducted for a period of one year from January 2017 to January 2018. We analysed 125 non-duplicate consecutive isolates of $S$. aureus isolated from various clinical specimens like pus, wound swab, aspirates, blood and sterile fluids. Age and sex of the patients were recorded. This study was approved by the Research and Ethical Committees of our Institute and informed consent was obtained from each patient.

\section{Clinical Samples and Bacterial Isolates}

During the period of one year, 125 clinical isolates of $S$. aureus were collected from Department of Microbiology and Department of Pharmacology, Government Medical College, Bettiah (West Champaran) Bihar and Associated Hospital. The bacteria which were consecutively isolated from patients in various wards and different specimens such as catheter, blood, wound, discharge, abscess, burn and so on were transported to Department of Microbiology and Department of Pharmacology, Government Medical College, Bettiah (West Champaran) Bihar and Associated Hospital. Identity of isolates were confirmed by standard microbiology tests including Gram staining, catalase, slide and tube coagulase, mannitol fermentation and production of DNase enzyme. ${ }^{6}$

\section{Antibiotic Susceptibility Test}

Antibiotic susceptibility testing was performed on MuellerHinton agar (HiMedia Laboratories, Mumbai, India) by KirbyBauer disk diffusion method as per CLSI guidelines using antibiotic disks (HiMedia Laboratories, Mumbai, India) such as Penicillin (10 units), Gentamicin $(10 \mu \mathrm{g})$, Tetracycline $(30 \mu \mathrm{g})$, Linezolid $(30 \mu \mathrm{g})$, Trimethoprim-Sulfamethoxazole $(1.25 / 23.75 \mu \mathrm{g})$, Cefoxitin $(30 \mu \mathrm{g})$, Erythromycin $(15 \mu \mathrm{g})$, Clindamycin $(2 \mu \mathrm{g})$ and ciprofloxacin $(5 \mu \mathrm{g})$. Staphylococcus aureus ATCC 25923 was used as standard quality control strain. ${ }^{7}$

\section{Methicillin Resistance Test}

Methicillin resistance amongst $S$. aureus was determined using Cefoxitin $(30 \mu \mathrm{g})$ disk on Mueller-Hinton agar as per CLSI guidelines, and results were read after 18 hours of incubation at $35^{\circ} \mathrm{C}$.

The $S$. aureus isolates which showed zone size $\geq 22 \mathrm{~mm}$ were considered Methicillin sensitive (MSSA) and those with zone size $\leq 21 \mathrm{~mm}$ were considered as Methicillin-resistant $S$. aureus (MRSA). Susceptibility of MRSA strains to Vancomycin was tested by agar dilution method as per CLSI guidelines by inoculating 0.5 McFarland bacterial suspensions on MuellerHinton agar (MHA) plates by using sterile swabs. The plates were analysed after 24 hours of incubation at $35^{\circ} \mathrm{C}$. Minimal inhibitory concentration (MIC) of Vancomycin of $\leq 2 \mu \mathrm{g} / \mathrm{mL}$ for $S$. aureus was considered as susceptible to Vancomycin.

\section{D-Zone Test (Disk Approximation Test)}

The isolates which were resistant to erythromycin were further tested by D-zone test which was performed as per CLSI guidelines by inoculating 0.5 McFarland bacterial suspensions on the Mueller-Hinton agar plates with the help of sterile swabs and placing the Erythromycin (E-15 $\mu \mathrm{g})$ and Clindamycin (CD-2 $\mu \mathrm{g}$ ) disks side-by-side with edge-to-edge distance of $15 \mathrm{~mm}$. Plates were analysed after 18 hours of incubation at $35^{\circ} \mathrm{C} .7$

\section{Phenotypic Inducible Resistance to Clindamycin by D- Test}

Isolates were plated on a Mueller-Hinton agar plate at a McFarland concentration of 0.5 to eventually cover the agar surface. Clindamycin and Erythromycin disks containing $2 \mu \mathrm{g}$ and $15 \mu \mathrm{g}$ each, respectively, were placed in the center of the plate separated by a distance of $15 \mathrm{~cm}$ between the edges. Plates were incubated at $37^{\circ} \mathrm{C}$ for $24 \mathrm{hrs}$. Inducible resistance to Clindamycin was defined as blunting of the clear circular area of no growth around the Clindamycin disk on the side adjacent to the Erythromycin disk and was designated D-test positive. Absence of a blunted zone of inhibition was designated D-test negative.

Three different Phenotypes of Erythromycin Resistant Isolates were interpreted as follows-

1. The Constitutive MLSB Phenotype (cMLSB): The $S$. aureus isolates resistant to both $\mathrm{E}$ (Zone size $\leq 13 \mathrm{~mm}$ ) and $C D$ (zone size $\leq 14 \mathrm{~mm}$ ) with circular shape of zone of inhibition if any around Clindamycin. This suggests selection of erm gene mutants.

2. The MS Phenotype: The $S$. aureus isolates which showed resistance to $\mathrm{E}$ (Zone size $\leq 13 \mathrm{~mm}$ ) and a complete circular zone of inhibition around CD (Zone size $\geq 21 \mathrm{~mm}$ ) indicated negative $\mathrm{D}$ zone test. This suggests resistance due to the msrA-coded active efflux pump mechanism.

3. The Inducible MLSB Phenotype (iMLSB): The $S$. aureus isolates, which showed resistance to $\mathrm{E}$ (Zone size $\leq 13 \mathrm{~mm}$ ) and susceptibility to CD (zone size $\geq 21 \mathrm{~mm}$ ) with flattening of zone of inhibition around Clindamycin in the area adjacent to the Erythromycin (D shaped zone), indicated positive D-zone test. This suggests a resistance phenotype due to expression of erm-gene coded methylases. 


\section{Statistical Analysis}

The collected data was statistically analysed using SPSS Data Editor Software, Chicago, version 20. The statistical association between inducible Clindamycin resistance phenotype and Methicillin-resistant S. aureus isolates were evaluated using Chi-square test and $\mathrm{p}<0.05$ was considered as statistically significant.

\section{RESULTS}

- Among 125 S. aureus isolates included in our study, 71 (57\%) were isolated from pus samples, $32(25.80 \%)$ were isolated from blood, 7 (5.2\%) were isolated from urine, $6(4.8 \%)$ were isolated from sputum and $9(7.2 \%)$ were isolated from miscellaneous samples as shown in [Table 1].

- Out of 125 S. aureus isolates, 46 (36.6\%) were Methicillin-resistant (MRSA) and 79 (63.4\%) were Methicillin-sensitive $S$. aureus (MSSA). Although, majority of the MRSA isolates (19) were derived from pus samples, the $S$. aureus isolates derived from postoperative wound infection (8) were mostly MRSA. This finding was found to be statistically significant $(p=$ 0.008903 ) [Table 2].

- $\quad$ Out of 125 S. aureus isolates of the MRSA, 46 (36.6\%) were derived from respectively Pus samples 19 (41.53\%), the $S$. aureus isolates derived from Wound samples were MRSA 8 (18.03\%), the $S$. aureus isolates derived from Blood samples were MRSA 10 (22.40\%), the $S$. aureus isolates derived from Miscellaneous samples were MRSA $6(13.66 \%)$ and the $S$. aureus isolates derived from Urine samples were MRSA 2 (3.75\%). This finding was found to be statistically significant $(\mathrm{p}=0.347491)$ [Table 3].

- $\quad$ The susceptible phenotype (E-S and CD-S) predominated in MSSA (39.75\%) as compared to MRSA (13.11\%). Whereas, the constitutive resistant (cMLSB) predominated in MRSA (50.27\%) as compared to MSSA (15.46\%). Both the MS phenotype and the inducible resistant (iMLSB) phenotypes predominated in MSSA (19.87 and $24.92 \%$ respectively) as compared to MRSA (22.40\% and $14.20 \%$ respectively). This finding was found to be highly significant $(\mathrm{p}<0.00001)$ [Table 4].
- $\quad$ Table 5 shows the distribution of S. aureus isolates on the basis of the source of collected samples (inpatients or outpatients) and their susceptibility pattern to Erythromycin and Clindamycin disks. Out of $125 \mathrm{~S}$. aureus isolates, 73 (58.40\%) were derived from samples of outpatients and 52 (41.60\%) were derived from samples of inpatients. The frequency of inducible Clindamycin resistant isolates (iMLSB phenotypes) and MS phenotypes predominated in samples of outpatients $[(15 ; 20.89 \%)$ and $(16 ; 21.23 \%)$, respectively] as compared to inpatients $(11 ; 21.15 \%)$ and $(11 ; 20.19 \%)$, respectively. This reveals that inducible Clindamycin resistance is both community (outpatients) as well as hospital (inpatients) acquired in our geographic location. However, constitutive resistant isolates (cMLSB phenotypes) predominated in samples of inpatients 18 $(28.20 \%)$ as compared to samples of outpatients 17 (27.29\%). This finding was found to be statistically significant $(\mathrm{p}=0.003089)$ [Table 5].

- Out of $125 \mathrm{~S}$. aureus isolates, majority were resistant to erythromycin $(70 \%, 88 / 125)$. A high percentage of Erythromycin resistant $S$. aureus isolates $(70 \%, 88 / 125)$ was detected, of which $86.89 \%$ (40/46) were MRSA and $60.25 \%(48 / 80)$ were MSSA. All the erythromycin resistant isolates were subjected to D-zone test and the resulting distribution of $S$. aureus isolates was shown in [Table 6].

- A total of $26 \mathrm{~S}$. aureus isolates showed inducible Clindamycin resistance by giving a positive D-zone test; hence, its prevalence was found to be $21.00 \%(26 / 125)$ with percentage distribution of cMLSB phenotype and MS phenotypes in all $S$. aureus isolates as $19.4 \%$ and $24.6 \%$ respectively [Table 6].

- $\quad$ The antimicrobial susceptibility test result of all the $26 S$. aureus isolates with iMLSB phenotype revealed that they were $100 \%$ sensitive to Vancomycin and Linezolid with moderate sensitivity $(71.14 \%)$ to Gentamicin, Cefuroxime and least sensitivity to (23.81\%) Doxycycline, (20.95\%) Ciprofloxacin as shown in [Table 6].

\begin{tabular}{|c|c|c|}
\hline Types of Sample & Samples Number & Samples Percentage \\
\hline Pus & 71 & $57.00 \%$ \\
\hline Blood & 32 & $25.80 \%$ \\
\hline Urine & 7 & $05.20 \%$ \\
\hline Sputum & 6 & $04.80 \%$ \\
\hline Miscellaneous* & 9 & $07.20 \%$ \\
\hline Total & $\mathbf{1 2 5}$ & $\mathbf{1 0 0 . 0 0}$ \\
\hline \multicolumn{2}{|c|}{} \\
\hline
\end{tabular}

[Note*:- Miscellaneous samples include ear discharge, abdominal drain fluid, throat swab, conjunctival swab and wound discharges etc.]

\begin{tabular}{|c|c|c|c|c|}
\hline \multirow[b]{2}{*}{ Sample } & \multicolumn{3}{|c|}{ Staphylococcus aureus } & \multirow{2}{*}{$\begin{array}{c}\text { Chi-square }(\chi 2) \\
\text { and } \\
* P \text {-value }\end{array}$} \\
\hline & $\begin{array}{c}\text { Resistant to Cefoxitin } \\
\text { (MRSA) N=27 (38.25\%) }\end{array}$ & $\begin{array}{l}\text { Susceptible to Cefoxitin } \\
\text { (MSSA) N=44 }(61.75 \%)\end{array}$ & $\begin{array}{l}\text { Total Isolates } \\
\mathrm{N}=71(100 \%)\end{array}$ & \\
\hline Pus due to any other cause, $\mathrm{N}(\%)$ & $19(34.23 \%)$ & $37(65.77 \%)$ & $56(77.89 \%)$ & \multirow{2}{*}{$\begin{array}{c}\mathrm{Chi}^{2}=6.8422 ; \mathrm{DF}=1 \\
\mathrm{P}=0.008903 \\
\text { statistically } \\
\text { significant }\end{array}$} \\
\hline Post-operative wound infection, N (\%) & $8(52.38 \%)$ & $8(47.62 \%)$ & $16(22.11 \%)$ & \\
\hline
\end{tabular}




\begin{tabular}{|c|c|c|c|c|}
\hline \multicolumn{5}{|c|}{$\begin{aligned} \text { N }=\text { Number of isolates } & \\
\text { MRSA } & =\text { Methicillin-resistant Staphylococcus aureus; } \\
\text { MSSA } & =\text { Methicillin-sensitive Staphylococcus aureus. } \\
\text { *p-value } & <0.05 \text { was considered as statistically significant. }\end{aligned}$} \\
\hline \multirow[b]{2}{*}{ Sample } & \multicolumn{3}{|c|}{\begin{tabular}{|r|} 
Staphylococcus aureus \\
\end{tabular}} & \multirow[b]{2}{*}{$\begin{array}{l}\text { Chi-square }(\chi 2) \\
\quad \text { and } \\
* \text { P-value }\end{array}$} \\
\hline & \begin{tabular}{|c|} 
Resistant to Cefoxitin \\
(MRSA) N= 46 \\
$(36.6 \%)$
\end{tabular} & $\begin{array}{c}\text { Susceptible } \\
\text { to Cefoxitin (MSSA) } \\
\mathrm{N}=79(63.4 \%)\end{array}$ & $\begin{array}{c}\text { Total Isolates } \\
\mathrm{N}=125(\mathbf{1 0 0} \%)\end{array}$ & \\
\hline Pus due to any other cause, $\mathrm{N}(\%)$ & $19(34.23 \%)$ & $37(65.77 \%)$ & $\begin{array}{c}56 \\
(44.4 \%) \\
\end{array}$ & \multirow{5}{*}{$\begin{array}{l}\mathrm{Chi}^{2}=9.6316 \\
\quad \mathrm{DF}=4 \\
\mathrm{P}=0.047113\end{array}$} \\
\hline Post-operative wound infection, $\mathrm{N}(\%)$ & $8(52.38 \%)$ & $8(47.62 \%)$ & $16(12.6 \%)$ & \\
\hline Blood Culture), N (\%) & $10(31.78 \%)$ & $22(68.22 \%)$ & $32(25.8 \%)$ & \\
\hline $\begin{array}{l}\text { Miscellaneous* } \\
\text { Sample, N (\%) } \\
\end{array}$ & $6(41.67 \%)$ & $9(58.33 \%)$ & $15(12 \%)$ & \\
\hline Urine due to any other cause, $\mathrm{N}(\%)$ & $2(30.77 \%)$ & $5(05.68 \%)$ & $\begin{array}{c}7 \\
(69.2 \%) \\
\end{array}$ & \\
\hline \multicolumn{5}{|c|}{ Table 3. Distribution of Staphylococcus aureus Isolates on the basis of Sample and Susceptibility to Cefoxitin (30 $\mu \mathrm{g}$ ) Disk } \\
\hline \multicolumn{5}{|c|}{$\begin{array}{c}\mathrm{N}=\text { Number of isolates. } \\
\text { MRSA }=\text { Methicillin-resistant Staphylococcus aureus; } \\
\text { MSSA = Methicillin-sensitive Staphylococcus aureus. } \\
\text { *p-value }<0.05 \text { was considered as statistically significant. }\end{array}$} \\
\hline
\end{tabular}

\begin{tabular}{|c|c|c|c|c|}
\hline \multirow[b]{2}{*}{ Antibiotic Susceptibility Pattern } & \multicolumn{3}{|c|}{ Staphylococcus aureus } & \multirow{2}{*}{$\begin{array}{c}\text { Chi-square }\left(\chi^{2}\right) \\
\text { and } \\
* P \text {-value }\end{array}$} \\
\hline & $\begin{array}{l}\text { MRSA N= } 46 \\
(36.6 \%)\end{array}$ & $\begin{array}{l}\text { MSSA N= } 79 \\
(63.4 \%)\end{array}$ & $\begin{array}{l}\text { Total Isolates } \\
\mathrm{N}=125(100 \%)\end{array}$ & \\
\hline E-S, CD-S (Susceptible phenotype) & $6(13.11 \%)$ & $32(39.75 \%)$ & $38(30.00 \%)$ & \multirow{4}{*}{$\begin{array}{c}\chi 2=84.001 \\
\mathrm{df}=3 \\
\mathrm{p}=0.00001\end{array}$} \\
\hline $\begin{array}{l}\text { E-R, CD-R (cMLSB phenotype) } \\
\text { D-zone test }=(-)\end{array}$ & $23(50.27 \%)$ & $12(15.46 \%)$ & $35(28.20 \%)$ & \\
\hline E-R, CD-S (MS phenotype) & $10(22.40 \%)$ & $16(19.87 \%)$ & $26(20.08 \%)$ & \\
\hline $\begin{array}{l}\text { E-R, CD-S (iMLSB phenotype) } \\
\text { D-zone test }=(+)\end{array}$ & $7(14.20 \%)$ & $20(24.92)$ & $27(21.00 \%)$ & \\
\hline \multicolumn{5}{|c|}{$\begin{array}{c}\text { Table 4. Distribution of Staphylococcus aureus isolates on the basis of their susceptibility to Erythromycin and Clindamycin } \\
\text { Disks placed adjacent to Each Other }\end{array}$} \\
\hline \multicolumn{5}{|c|}{$\begin{array}{c}\mathrm{N}=\text { Number of isolates. MRSA= Methicillin-resistant Staphylococcus aureus; MSSA= Methicillin sensitive Staphylococcus aureus; } \\
\mathrm{E}=\text { Erythromycin }(15 \mu \mathrm{g}) \text { disk; } \mathrm{CD}=\mathrm{Clindamycin}(2 \mu \mathrm{g}) \text { disk; } \mathrm{S}=\text { Sensitive; } \mathrm{R}=\text { Resistant; cMLSB phenotype= isolates with } \\
\text { constitutive resistance to clindamycin; MS phenotype= isolates with susceptibility to Clindamycin (circular zone of inhibition) } \\
\text { and negative D-zone test; iMLSB phenotype= isolates with inducible resistance to Clindamycin and positive D } \\
\text { zone test. *P-value }<0.05 \text { was considered as statistically significant. }\end{array}$} \\
\hline
\end{tabular}

\begin{tabular}{|c|c|c|c|c|}
\hline \multirow[b]{2}{*}{ Antibiotic Susceptibility Pattern } & \multicolumn{3}{|c|}{ Staphylococcus aureus } & \multirow{2}{*}{$\begin{array}{l}\text { Chi-square }(\chi 2) \\
\text { and } \\
\quad \text { *P-value }\end{array}$} \\
\hline & $\begin{array}{l}\text { Outpatient } \mathrm{N}=73 \\
\quad(58.40 \%)\end{array}$ & $\begin{array}{l}\text { Inpatient } \mathrm{N}=52 \\
\quad(41.60 \%)\end{array}$ & $\begin{array}{l}\text { Total Isolates } \\
\mathrm{N}=125(100 \%)\end{array}$ & \\
\hline E-S, CD-S (Susceptible phenotype) & $25(34.59 \%)$ & $13(23.56 \%)$ & $38(30.00 \%)$ & \multirow{4}{*}{$\begin{array}{c}\chi 2=13.8692 ; \\
\mathrm{df}=3 \\
\mathrm{p}=0.003089 \\
\text { statistically } \\
\text { significant }\end{array}$} \\
\hline E-R, CD-R (cMLSB phenotype);D-zone test $=(-)$ & $17(23.29 \%)$ & $18(35.10 \%)$ & $35(28.20 \%)$ & \\
\hline E-R, CD-S (MS phenotype) & $16(21.23 \%)$ & $10(20.19 \%)$ & $26(20.08 \%)$ & \\
\hline $\begin{array}{l}\text { E-R, CD-S (iMLSB phenotype) } \\
\text { D-zone test }=(+)\end{array}$ & $15(20.89 \%)$ & $11(21.15 \%)$ & $26(21.00 \%)$ & \\
\hline \multicolumn{5}{|c|}{$\begin{array}{c}\text { Table 5. Distribution of Staphylococcus aureus Isolates on the basis of their Susceptibility to Erythromycin and Clindamycin } \\
\text { Disks placed adjacent to Each Other }\end{array}$} \\
\hline \multicolumn{5}{|c|}{$\begin{array}{l}\mathrm{N}=\text { Number of isolates. } \mathrm{E}=\text { Erythromycin }(15 \mu \mathrm{g}) \text { disk; } \mathrm{CD}=\text { Clindamycin }(2 \mu \mathrm{g}) \text { disk; } \mathrm{S}=\text { Sensitive; } \mathrm{R}=\text { Resistant; cMLSB phenotype= } \\
\text { isolates with constitutive resistance to Clindamycin; } \mathrm{MS} \text { phenotype= isolates with susceptibility to Clindamycin (circular zone of } \\
\text { inhibition) and negative D-zone test; iMLSB phenotype= isolates with inducible resistance to Clindamycin and positive D-zone test. } \\
\text { *P-value }<0.05 \text { was considered as statistically significant. }\end{array}$} \\
\hline
\end{tabular}

\begin{tabular}{|c|c|c|}
\hline \multirow{2}{*}{ Antibiotic Tested } & \multicolumn{2}{|c|}{ iMLSB Phenotypes N= 26 (100\%) } \\
\cline { 2 - 3 } & Resistant N (\%) & Sensitive N (\%) \\
\hline Vancomycin & $0(00.00 \%)$ & $26(100 \%)$ \\
\hline Linezolid & $0(00.00 \%)$ & $26(100 \%)$ \\
\hline Ciprofloxacin & $21(79.05 \%)$ & $5(20.95 \%)$ \\
\hline Cefoxitin & $6(24.76 \%)$ & $20(75.24 \%)$ \\
\hline Gentamicin & $5(22.86 \%)$ & $21(71.14 \%)$ \\
\hline Cefuroxime & $6(22.86 \%)$ & $20(71.14 \%)$ \\
\hline
\end{tabular}




\begin{tabular}{|c|c|c|}
\hline Amoxyclav & $10(36.19 \%)$ & $16(63.81 \%)$ \\
\hline Amoxicillin & $1(33.33 \%)$ & $2(67.77 \%)$ \\
\hline Doxycycline & $20(76.19 \%)$ & $6(23.81 \%)$ \\
\hline Levofloxacin & $10(40 \%)$ & $16(60 \%)$ \\
\hline Table 6. Antibiotic Susceptibility Pattern of inducible Clindamycin resistant Staphylococcus aureus Isolates \\
(iMLSB phenotypes) derived from Infection \\
\hline \multicolumn{2}{|c|}{ N= Number of Isolates } \\
\hline
\end{tabular}

\section{DISCUSSION}

In emergence of multidrug-resistant $S$. aureus, it is often crucial to determine antimicrobial susceptibility of all clinical isolates for optimal therapy of infected patients. ${ }^{[8]}$ Due to limited range of antibiotics available for the treatment of Methicillin-resistant staphylococcal infections and the known limitations of Vancomycin and Clindamycin should be considered for the management of serious soft tissue infections with MRSA that are sensitive to Clindamycin.[9] However, Clindamycin resistance can develop in staphylococcal isolates with inducible phenotype and from such isolates spontaneous constitutively resistant mutants have arisen during Clindamycin therapy.[10] Reporting $S$. aureus as susceptible to Clindamycin without checking for inducible resistance may result in institution of inappropriate Clindamycin therapy and hence therapeutic failure. On the other hand, negative result for inducible Clindamycin resistance (MS phenotype) confirms true Clindamycin susceptibility and as these isolates do not become resistant to it during therapy Clindamycin can act as a good therapeutic option in such cases.[11] The true sensitivity to Clindamycin can only be judged after performing D-zone test on the erythromycin resistant $S$. aureus isolates. ${ }^{[8]}$

Resistance is induced by the binding of a macrolide to upstream translational attenuator sequences, leading to changes in mRNA secondary structure, exposure of the ribosomal binding site and expression of the multiallele plasmid-borne erythromycin ribosomal methylase (erm) gene that causes the production of the methylase enzymes. These enzymes cause methylation of the A2058 residue, located in the conserved domain $\mathrm{V}$ of the 23S rRNA component of the $50 \mathrm{~S}$ ribosomal subunit, which leads to cross resistance and the formation of the inducible phenotype (iMLSB) of the resistance pattern.[12,13] Alterations in these 5' upstream sequences including deletions, duplications and other mutations lead to constitutive expression of the methylase gene and constitutive MLSB resistance. Recent evidence also proves that constitutive resistance to Clindamycin in $S$. aureus prevents the inhibition of toxin production and fails to inhibit growth.[14] Interestingly, the streptogramin B and A combination quinupristin/dalfopristin appears to retain its activity against cMLSB strains of Staphyloccci, although the presence of the cMLSB phenotype changes the agent's activity from bactericidal to bacteriostatic.[15] Treatment of infections by the iMLSB and cMLSB resistant phenotypes with Clindamycin will result in failure. Routine susceptibility testing can easily detect cMLSB phenotypes, but the real challenge lies in correctly identifying those iMLSB strains that are Clindamycin sensitive in vitro, but result in therapeutic failure in vivo. This can be achieved by testing the isolates using the D-test in accordance with CLSI guidelines.[16] In this test, 14/15 membered Macrolides (strong methylase inducers) and Clindamycin disks are placed $15 \mathrm{~mm}$ apart edge-to-edge on a lawn culture of Staphylococcus spp. isolates and incubated overnight. This precludes the prescription of Clindamycin as a therapeutic drug in such scenarios. The benefit of routine D-testing is that we can clearly identify those strains that remain susceptible to Clindamycin despite being resistant to Macrolides. Isolates with the inducible resistance phenotype should be reported as Clindamycin resistant. On the other hand, negative result for inducible Clindamycin resistance confirms Clindamycin susceptibility and serves as a very good therapeutic option.[15] The true sensitivity to Clindamycin can only be judged after performing D-zone test on the erythromycin resistant $S$. aureus isolates. ${ }^{[8]}$

In our study, we have included $125 \mathrm{~S}$. aureus isolates derived from pus 19 (41.53\%), post-operative wound infection 8 (18.03\%), blood samples were 10 (22.40\%), Miscellaneous Samples were 6 (13.66\%) and urine sample 2 (3.75\%) from both outpatients and inpatients of Orthopaedic Department of our Institution. The prevalence of Methicillin resistance amongst all $S$. aureus isolates was found to be $36.6 \%$. The prevalence of MRSA in other studies was found to vary from $12.9 \%$ to $49.8 \%$ with the geographical area under study.[17,8]

In the present study, the susceptible phenotypes (susceptible to both Erythromycin and Clindamycin) were found to predominate in MSSA (39.75\%) as compared to MRSA (13.11\%). A high percentage of Erythromycin resistant $S$. aureus isolates $(70 \%, 88 / 125)$ were detected, of which 86.89\% (40/46) were MRSA and 60.25\% (48/79) were MSSA. All these were tested for D-zone test. Amongst them maximum isolates $(40.29 \%, 35 / 88)$ were of cMLSB phenotype (D-zone test negative), followed by constitutive and inducible resistance phenotype. This suggests that majority of the Erythromycin resistant $S$. aureus isolates can still be treated successfully with Clindamycin. In our study the percentage of inducible Clindamycin resistance (iMLSB phenotype, which gave positive D-zone test) amongst Erythromycin resistant isolates was 30\% (26/88). This is in agreement to studies from Chandigarh and Bangalore, which reported inducible resistance to be $26.1 \%$ and $22.2 \%$ respectively among erythromycin resistant isolates. While in two different studies from Karnataka, the iMLSB phenotype was seen to be quite high in $63 \%$ and $55.26 \%$ isolates respectively among the erythromycin resistant strains of $S$. aureus. ${ }^{[13,18]}$ In the present study, it was found that the percentage of the constitutive resistant (cMLSB) predominated in MRSA (50.27\%) as compared to MSSA (15.46\%). Both the MS phenotype and the inducible resistant (iMLSB) phenotypes predominated in MSSA (19.87 and $24.92 \%$ respectively) as compared to MRSA $(22.40 \%$ and $14.20 \%$ respectively). Our data show that the MLSBi resistance phenotype is prevalent in clinical laboratories in the Bettiah area; however, the incidence differs from that reported in other Indian cities and Internationally few studies have shown higher percentage of inducible resistance in MSSA as compared to MRSA.[19,20] The cost benefit of routinely performing the D-test must be evaluated in each 
laboratory setting after first determining the incidence of the MLSBi. For example, in of our hospitals, the incidence of the ER-R/I CD-S phenotype in MRSA was low, 14.20\%. But other studies from Kolkata, which showed inducible resistance and constitutive resistance in MRSA compared to MSSA (22.6\%, $35.5 \%$, and $11.8 \%, 11.8 \%$, respectively), whereas, MS phenotype predominated in MSSA compared to MRSA (17.6\% and $16.1 \%$ respectively).[21] A study from Chandigarh also showed higher inducible and constitutive resistance in MRSA isolates (20\% and $46 \%$, respectively) as compared to MSSA isolates $(17.3 \%$ and $10 \%$, respectively), whereas MS phenotype was predominant among MSSA (37.3\%) as compared to MRSA (16\%).[22] Another study from Karnataka also showed higher constitutive and inducible resistance amongst MRSA (15.4\% and 38.5\%, respectively) as compared to MSSA ( $0 \%$ and $12.9 \%$ respectively). However, they did not report any MS phenotype.[23] A study from Maharashtra also showed higher percentage of inducible resistance amongst MRSA as compared to MSSA (27.6\% and 1.6\% respectively). However, they also reported higher MS phenotype amongst MRSA (24.3\%) than in MSSA (4\%), and constitutive resistance of $7.3 \%$ in MRSA and none amongst MSSA.[8]

In our study, higher incidence of inducible Clindamycin resistance was detected among isolates derived from outpatients (community acquired) as compared to inpatients or hospital acquired (58.40\% and $41.60 \%$, respectively). This finding was similar to another study, which also reported higher incidence of inducible Clindamycin resistance from community $(66.67 \%)$ than from hospital (33.33\%).[24] This may be due to the fact that Clindamycin being an oral drug has been increasingly prescribed by the physicians in outdoor clinical settings, thus leading to increased incidence of community-acquired inducible Clindamycin resistance.

In our study, we also looked forward for treatment options for inducible Clindamycin resistant S. aureus isolates by detecting their antimicrobial susceptibility to various other antibiotics. It was found that all isolates with iMLSB phenotype were $100 \%$ susceptible to Linezolid and Vancomycin followed by moderate susceptibility $(71,14 \%)$ to Gentamicin, Cefuroxime and least susceptibility to Doxycycline and Ciprofloxacin $(23.81 \%$ and $20.95 \%$, respectively). This finding is in concordance to other studies that also found that all the iMLSB isolates were uniformly susceptible to Linezolid and Vancomycin. [22,24,25]

\section{CONCLUSION}

In our study, we also looked forward for treatment options for inducible clindamycin resistant $S$. aureus isolates by detecting their antimicrobial susceptibility to various other antibiotics. It was found that all isolates with iMLSB phenotype were $100 \%$ susceptible to Linezolid and Vancomycin followed by moderate susceptibility $(71,14 \%)$ to Gentamicin and Cefuroxime and least susceptibility to Doxycycline and Ciprofloxacin $(23.81 \%$ and $20.95 \%$, respectively). This finding is in concordance to other studies that also found that all the iMLSB isolates were uniformly susceptible to Linezolid and Vancomycin.

\section{REFERENCES}

[1] Deleo FR, Otto M, Kreiswirth BN, et al. Communityassociated methicillin-resistant staphylococcus aureus. Lancet 2010;375(9725):1557-68.
[2] Juyal D, Shamanth AS, Pal S, et al. The prevalence of inducible clindamycin resistance among staphylococci in a tertiary care hospital - a study from the Garhwal hills of Uttarakhand, India. J Clin Diagn Res 2013;7(1):61-5.

[3] Jorgensen JH, Crawford SA, McElmeel ML, et al. Detection of inducible clindamycin resistance of staphylococci in conjunction with performance of automated broth susceptibility testing. J Clin Microbiol 2004;42(4):1800-2.

[4] Patel M, Waites KB, Moser SA, et al. Prevalence of inducible clindamycin resistance among community and hospital associated Staphylococcus aureus isolates. J Clin Microbiol 2006;44(7):2481-4.

[5] Clinical and Laboratory Standards Institute (CLSI). Performance standards for antimicrobial susceptibility testing. Twenty-second Informational Supplement Document M100-S22. Wayne, PA, USA: CLSI, 2013.

[6] Baird P. Staphylococcus: cluster-forming Gram positive cocci. In: Collee JG, Fraser AG, Marmion BP, et al. eds. Mackie and McCartney Practical Medical Microbiology. 14th edn. New York: Churchill Livingstone 1996: p. 245-61.

[7] Clinical and Laboratory Standards Institute. Performance standards for antimicrobial susceptibility testing: Twenty-Fourth Informational Supplement Document M100-S24. Wayne: CLSI, 2014.

[8] Deotale V, Mendiratta DK, Raut U, et al. Inducible clindamycin resistance in Staphylococcus aureus isolated from clinical samples. Indian J Med Microbiol 2010;28(2):124-6.

[9] Rao GG. Should clindamycin be used in treatment of patients with infections caused by erythromycin resistant staphylococci? J Antimicrob Chemother 2000;45(5):715.

[10] Yilmaz G, Aydin K, Iskender S, et al. Detection and prevalence of inducible clindamycin resistance in staphylococci. J Med Microbiol 2007;56(Pt 3):342-5.

[11] Fiebelkorn KR, Crawford SA, McElmeel ML, et al. Practical disk diffusion method for detection of inducible clindamycin resistance in Staphylococcus aureus and coagulase negative staphylococci. J Clin Microbiol 2003;41(10):4740-4.

[12] Weisblum B. Erythromycin resistance by ribosome modification. Antimicrob Agents Chemother 1995;39(3):577-85.

[13] Roberts M, Sutcliffe J, Courvalin P, et al. Nomenclature for macrolide and macrolide-lincosamidestreptogramin B resistance determinants. Antimicrob Agents Chemother 1999;43(12):2823-30.

[14] Lewis JS 2nd, Jorgensen JH. Inducible clindamycin resistance in Staphylococci: should clinicians and microbiologists be concerned? Clin Infect Dis 2005;40(2):280-5.

[15] Fuchs PC, Barry AL, Brown SD. Bactericidal activity of quinupristin-dalfopristin against Staphylococcus aureus: clindamycin susceptibility as a surrogate indicator. Antimicrob Agents Chemother 2000;44(10):2880-2. 
[16] Clinical and Laboratory Standards Institute. Performance standards for antimicrobial susceptibility testing: Twenty-Fourth Informational Supplement M100-S24. Wayne: CLSI, 2014.

[17] Poddar CK, Kumar R, Sinha RN, et al. Microbiological surveillance in the intensive care unit: a tertiary hospital experience in Koshi Area (Northern Bihar) India. Journal of Evolution of Medical and Dental Sciences 2014;3(34):9050-6.

[18] Ajantha GS, Kulkarni RD, Shetty J, et al. Phenotypic detection of inducible clindamycin resistance among Staphylococcus aureus isolates by using the lower limit of recommended inter-disk distance. Indian J Pathol Microbiol 2008;51(3):376-8.

[19] Schreckenberger PC, Ilendo E, Ristow KL. Incidence of constitutive and inducible clindamycin resistance in Staphylococcus aureus and coagulase-negative staphylococci in a community and a tertiary care hospital. J Clin Microbiol 2004;42(6):2777-9.

[20] Levin TP, Suh B, Axelrod P, et al. Potential clindamycin resistance in clindamycin susceptible, erythromycinresistant Staphylococcus aureus: report of a clinical failure. Antimicrob Agents Chemother 2005;49(3):1222-4.
[21] Kumar S, Bandopadhyay M, Bhattacharya K, et al. Inducible clindamycin resistance in staphylococcus isolates from a tertiary care hospital in Eastern India. Ann Trop Med Public Health 2012;5(5):468-70.

[22] Gupta V, Datta P, Rani H, et al. Inducible clindamycin resistance in Staphylococcus aureus: a study from north India. J Postgrad Med 2009;55(3):176-9.

[23] Ciraj AM, Vinod P, Sreejith G, et al. Inducible clindamycin resistance among clinical isolates of Staphylococci. Indian J Pathol Microbiol 2009;52(1):49-51.

[24] Sasirekha B, Usha MS, Amruta JA, et al. Incidence of constitutive and inducible clindamycin resistance among hospital-associated Staphylococcus aureus. 3 Biotech 2014;4(1):85-9.

[25] Pal N, Sharma B, Sharma S, et al. Detection of inducible clindamycin resistance among staphylococcal isolates from different clinical specimens in western India. J Postgrad Med 2010;56(3):182-5. 